Tohoku J. Exp. Med., 2003, 199, 59-68

\title{
Hyperuricemia in Hypothyroidism: Is It Associated with Post-Insulin Infusion Glycemic Response?
}

\author{
Nuran Dariyerlí, Gülnur Andícan, ${ }^{1}$ Alp Burak Çatakoğlu, ${ }^{2}$ Hüsrev \\ Hatemi $^{3}$ and GÜlden BurçAK ${ }^{1}$ \\ Department of Physiology, ${ }^{1}$ Department of Biochemistry, Cerrahpasa \\ Medical Faculty, İstanbul University, ${ }^{2}$ Department of Cardiology, Florance \\ Nightingale Hospital, Kadir Has University, ${ }^{3}$ Department of Internal Medicine, \\ Cerrahpaşa Medical Faculty, İstanbul University, I stanbul, Turkey
}

\begin{abstract}
Dariyerli, N., Andican, G., ÇatakoĞlu, A.B., Hatemi, H. and Burçak, G. Hyperuricemia in Hypothyroidism: Is It Associated with Post-Insulin Infusion Glycemic Response? Tohoku J. Exp. Med., 2003, 199 (2), 59-68— This experimental study was designed to examine whether hyperuricemia in hypothyroidism is associated with insulin resistance. For induction of hypothyroidism, rabbits ( $n=12$ ) were administered methimazole orally (75 mg/100 g food) for 30 days. $T_{3}$, $\mathrm{T}_{4}$ and TSH values measured in plasma prior to and at the end of the experimentation period revealed the establishment of hypothyroidism. In the euthyroid and hypothyroid states of rabbits, crystalline porcine insulin was administered (0.1 unit/kg body weight) intraperitoneally and plasma glucose was measured at 0,15 , 30, 45 and 60 minutes. Sum of post insulin infusion glucose values was considered to reflect insulin resistance. Creatinine clearance (GFR) and uric acid clearance $\left(\mathrm{C}_{\mathrm{uA}}\right)$ were determined. Additionally, triglycerides were measured in plasma and $\mathrm{Mg}^{2+}$ both in erythrocytes and in plasma. Due to hypothyroidism: i) The glycemic response to insulin was not altered. ii) GFR and $\mathrm{C}_{\mathrm{uA}}$ were both decreased but $\mathrm{C}_{\mathrm{uA}} /$ GFR unchanged. iii) Triglycerides in plasma decreased. iv) $\mathrm{Mg}^{2+}$ concentration increased in plasma whereas decreased in erythrocytes. Several associations were observed between the variables on correlation analysis. On the basis of our data, it could be suggested that insulin resistance does not exist in hypothyroidism. Hyperuricemia observed in hypothyroidism should be considered to be secondary to decreased renal excretion but not as an indicator of insulin resistance.

hypothyroidism; hyperuricemia; post insulin infusion glycemic response; triglycerides; magnesium

(C) 2003 Tohoku University Medical Press
\end{abstract}

Received September 25, 2002; revision accepted for publication February 12, 2003.

Address for reprints: Nuran Darıyerli, Department of Physiology, Cerrahpaşa Medical Faculty, İstanbul University, Bosna bulvarı Ata 2 Sitesi, Erguvan cad. 79/7 Çengelköy, Uskudar, İstanbul, Turkey.

e-mail: dariyerli@yahoo.com 
Hyperuricemia and insulin resistance are strikingly associated, as observed in obesity, hypertriglyceridemia, impaired glucose tolerance and hypertension. Additionally, hyperuricemia and insulin resistance are both more common in men than in premenopausal women (Mikkelson et al. 1965; Modan et al. 1987). Recently, hyperuricemia has been suggested as a simple marker of insulin resistance in nondiabetic subjects even in the absence of signs and symptoms of gout (Vuorinen-Markkola and Yki-Järvinen 1994). Earlier studies have shown that both abnormal carbohydrate tolerance (Shah et al. 1975) and hyperuricemia (Erickson et al. 1994; Yokogoshi and Saito 1996) exist in patients with hypothyroidism. However, it is unknown whether hyperuricemia predicts insulin resistance in hypothyroidism. In this context, the present study was designed to examine whether hyperuricemia in hypothyroidism is associated with the response to intravenously administered insulin as measured by plasma glucose levels (Shah et al. 1975). Additionally considering the key role of intracellular $\mathrm{Mg}^{2+}$ in insulin mediated glucose uptake (Paolisso and Ravussin 1995), whether erythrocyte $\mathrm{Mg}^{2+}$ concentration is associated with the glycemic response to administered insulin in hypothyroidism was also determined.

To investigate these associations in a well defined system we chose to study in a rabbit model of hypothyroidism induced by methimazole. Thus obesity untreated hypertension, elevated triglycerides and impaired glucose tolerance related to hyperuricemia on one hand and hyperinsulinemia on the other are being avoided and directly hypothyroidism induced intraindividual changes could be shown up (Vuorinen-Markkola and Yki-Järvinen 1994).

\section{MATERIALS AND METHODS}

\section{Animals and experimental design}

Twelve rabbits, 1 month old and $1.8-2 \mathrm{~kg}$ body weight were obtained from the Laboratory Animal Service of the University of Istanbul.
The rabbits cared for in accordance with the Guide for the Care and Use of Laboratory Animals (1996) were permitted ad libitum access to food and drinking water for 10 days prior to experimental procedure. Rabbits were treated with methimazole for 30 days $(75 \mathrm{mg} / 100 \mathrm{~g}$ food). Prior to methimazole treatment and at the end of the experimentation period the following were done:

Twenty four hour urine collection: Prior to urine collection, the urinary bladder was first emptied completely through an indwelling sterile catheter and then the rabbit put into the special plexiglass cage for 24 hours. At the end of this period the bladder was re-emptied and this portion was added to that collected in the cage.

Blood sampling: After an overnight fast, between 9-11 a.m. heparinized blood samples were taken from each experimental animal by heart puncture for the analysis of biochemical parameters.

Measurement of post-insulin infusion glycemic response: For the determination of the glycemic response to administered insulin, crystalline porcine insulin ( $0.1 \mathrm{unit} / \mathrm{kg}$ body weight) was rapidly administered intraperitoneally. Heparinized blood was obtained via the ear vein at 15 minutes intervals for 60 minutes and plasma glucose immediately measured. Sum of $0,15,30,45$ and 60 minutes post-insulin infusion glucose levels (glycemic response) was considered as the measure of the response to insulin, the higher the glycemic response the more insulin resistant the subject (Shah et al. 1975). The tests were performed at the same time of the day in all cases to avoid circadian fluctuations.

\section{Biochemical analysis}

Plasma, separated promptly by low speed centrifugation and kept at $4^{\circ} \mathrm{C}$ was analysed for $\mathrm{T}_{3}, \mathrm{~T}_{4}$, TSH, uric acid, creatinine and triglycerides and urine for uric acid and creatinine. $\mathrm{Mg}^{2+}$ was analysed both in the plasma and the 
erythrocytes. The erythrocytes after being washed three times with $9 \mathrm{~g} /$ liter $\mathrm{NaCl}$ were hemolysed by dilution with four fold water and erythrocyte $\mathrm{Mg}^{2+}$ expressed as $\mathrm{mg} / \mathrm{g} \quad \mathrm{Hb} . \mathrm{T}_{3}$, $\mathrm{T}_{4}$ and TSH analyses were performed by RIA. Uric acid, creatinine, triglyceride, $\mathrm{Mg}^{2+}$, glucose was measured by spectrophotometrical methods using the respective kits (Randox, Crumlin, UK) and hemoglobin analysis.

\section{Statistical analysis}

The individual changes induced by methimazole were statistically evaluated by Student's paired $t$-test. Pearson-Bravis correlation cofficient was determined to define the relationships among the variables measured.

\section{RESULTS}

Prior to administration of methimazole, the baseline plasma values of $\mathrm{T}_{3}, \mathrm{~T}_{4}$ and TSH were found to be $63.08 \pm 12.00 \mathrm{ng} / 100 \mathrm{ml}, 2.44 \pm 0.48$ $\mu \mathrm{g} / 100 \mathrm{ml}$ and $0.02 \pm 0.01 \mu \mathrm{IU} / \mathrm{ml}$, respectively. At the end of the experimental period the measured values for $\mathrm{T}_{3}, \mathrm{~T}_{4}$ and $\mathrm{TSH}$ were $(47.24 \pm 10.68 \mathrm{ng} / 100 \mathrm{ml}) \quad(1.52 \pm 0.52 \mu \mathrm{g} / 100 \mathrm{ml})$ and $(0.07 \pm 0.02 \mu \mathrm{IU} / \mathrm{ml})$, respectively. A significant decrease in both $\mathrm{T}_{3}$, and $\mathrm{T}_{4}$ but a significant increase in TSH confirmed the estab- lishment of primary hypothyroidism in the animals (Table 1).

As shown in Table 1 due to the established hypothyroidism, uric acid concentration was found to be significantly $(p<0.001)$ increased in the plasma (Fig. 1a) whereas $(p<0.05)$ decreased significantly in the urine (Fig. 1b). Uric acid clearance was found to be significantly $(p<0$. 001) decreased due to hypothyroidism (Fig. 1c). Glomerular filtration rate was also found to be lower in the hypothyroid state when compared to the euthyroid state $(p<0.05)$. However, fractional excretion of uric acid as determined by $\mathrm{C}_{\mathrm{uA}} /$ glomerular filtration rate $\left(\mathrm{C}_{\mathrm{uA}} / \mathrm{GFR}\right)$ was found that not to be altered (Fig. 1d). Sum of 0 , $15,30,45$ and 60 minutes post insulin infusion glucose levels were found not to be altered due to the induction of hypothyroidism (Fig. 1e). Plasma triglyceride concentration was found to be decreased $(p<0.01)$ due to hypothyroidism (Fig. 1f). Plasma $\mathrm{Mg}^{2+}$ concentration was found to be increased $(p<0.01)$ whereas erythrocyte $\mathrm{Mg}^{2+}$ decreased $(p<0.01)$ due to hypothyroidism (Figs. $1 \mathrm{~g}$ and $1 \mathrm{~h}$ ).

As to our findings on correlation analysis (Tables 2 and 3): Post insulin infusion sum glucose values were found to be correlated with TSH values in the hypothyroid state $(r=0.76$,

TABLE 1. The Laboratory data in euthyroid and hypothyroid states of experimental animals

\begin{tabular}{lcc}
\hline \multicolumn{1}{c}{ Parameter } & Euthyroid & Hypothyroid \\
\hline $\mathrm{T}_{3}(\mathrm{ng} / 100 \mathrm{ml})$ & $63.08 \pm 12.00$ & $47.24 \pm 10.68^{* * *}$ \\
$\mathrm{~T}_{4}(\mu \mathrm{g} / 100 \mathrm{ml})$ & $2.44 \pm 0.48$ & $1.52 \pm 0.52^{* * *}$ \\
$\mathrm{TSH}(\mu \mathrm{IU} / \mathrm{ml})$ & $0.02 \pm 0.01$ & $0.07 \pm 0.02^{* * *}$ \\
Uric acid (plasma) $(\mathrm{mg} / 100 \mathrm{ml})$ & $0.55 \pm 0.17$ & $0.84 \pm 0.20^{* * *}$ \\
Uric acid (urine) $(\mathrm{mg} / 100 \mathrm{ml})$ & $10.51 \pm 2.68$ & $7.81 \pm 1.93^{*}$ \\
Clearence of uric acid $\left(\mathrm{C}_{\mathrm{uA}}\right)(\mathrm{ml} / \mathrm{min})$. & $1.93 \pm 0.56$ & $0.97 \pm 0.48^{* * *}$ \\
Clearence of creatinine $(\mathrm{GFR})(\mathrm{ml} / \mathrm{min})$. & $5.77 \pm 3.20$ & $2.90 \pm 2.31^{*}$ \\
$\mathrm{C}_{\mathrm{uA}} / \mathrm{GFR}$ & $0.60 \pm 0.07$ & $0.77 \pm 0.07$ \\
Sum Glucose & $409 \pm 79.4$ & $352.3 \pm 71.9$ \\
Triglycerides $(\mathrm{mg} / 100 \mathrm{ml})$ & $76.75 \pm 23.20$ & $42.24 \pm 14.86^{* *}$ \\
$\mathrm{Mg}^{2+}$ Plasma $(\mathrm{mg} / 100 \mathrm{ml})$ & $1.90 \pm 0.4$ & $2.5 \pm 0.5^{* *}$ \\
$\mathrm{Mg}^{2+}$ Erythroycte $(\mathrm{mg} / \mathrm{g} \mathrm{Hb})$ & $0.70 \pm 0.1$ & $0.50 \pm 0.2^{* *}$ \\
\hline
\end{tabular}

Data are the means \pm s.D. $(n=12)$.

${ }^{*} p<0.05 . \quad{ }^{* *} p<0.01 . \quad{ }^{* * *} p<0.001$. 

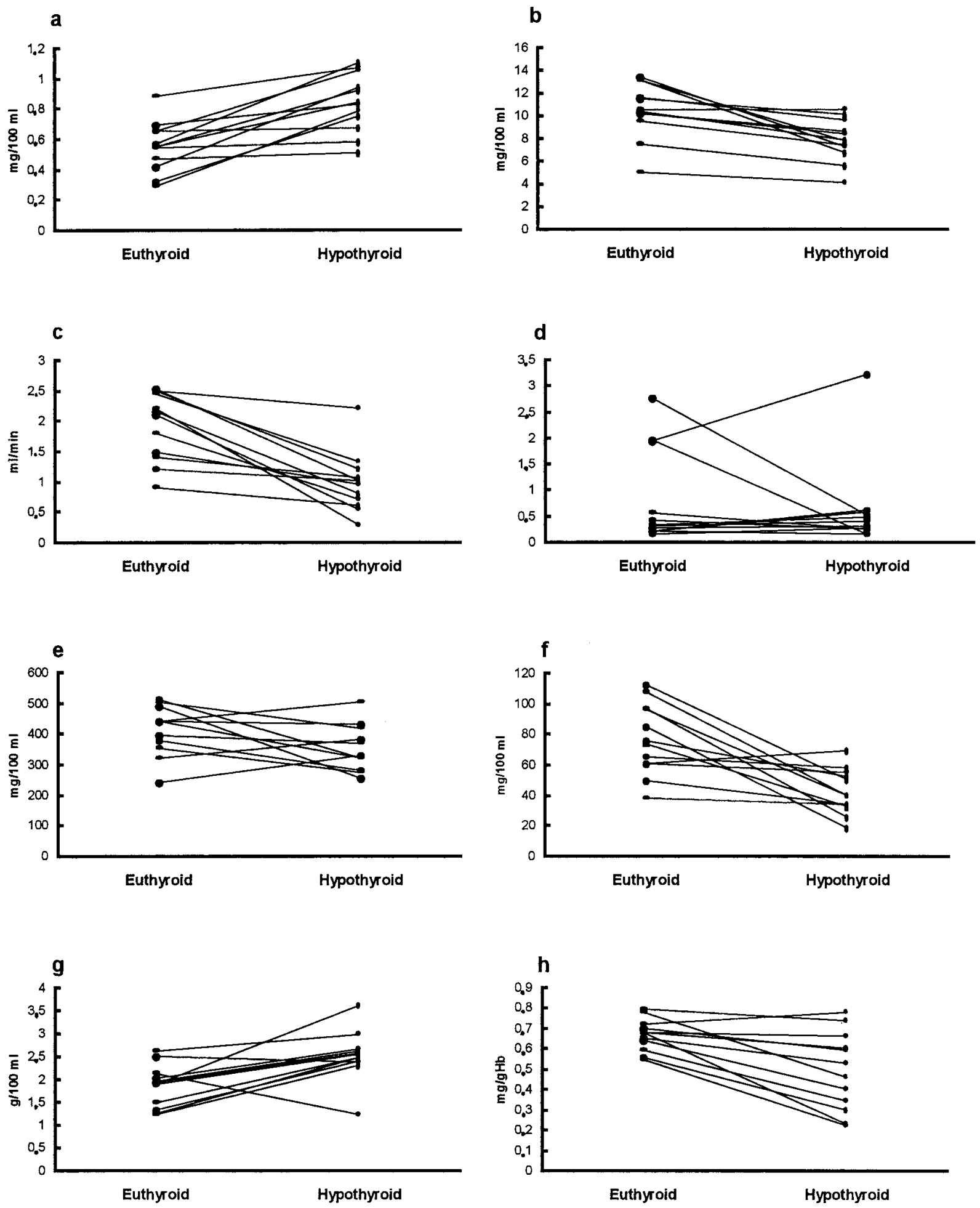

Fig. 1. Hypothyroidism induced intraindividual changes in the parameters. a, Plasma uric acid; b, Urinary uric acid; c, Clearance of uric acid; d, $\mathrm{C}_{\mathrm{uA}} / \mathrm{GFR}$; e, Sum glucose; f, Triglycerides; g, Plasma magnesium; h, Erythrocyte magnesium. 
$p<0.01)$. Post insulin infusion sum glucose values were found to be correlated with GFR in the hypothyroid state $(r=0.75, p<0.001)$. Triglyceride values were found to be inversely correlated with $\mathrm{T}_{3}$ values in the hypothyroid state $(r=-0.60, p<0.05)$ and correlated with TSH values in the euthyroid state $(r=0.61, p<0.05)$. Plasma uric acid concentration was found to be correlated to $\mathrm{T}_{4}$ values both in the hypothyroid and euthyroid states $(r=0.72, p<0.01, r=0.58$, $p<0.05)$, respectively. Plasma $\mathrm{Mg}^{2+}$ values were found to be correlated with erythrocyte $\mathrm{Mg}^{2+}$ values in the euthyroid state $(r=0.61, p<$ 0.05). Plasma and erythrocyte $\mathrm{Mg}^{2+}$ values were found to be inversely correlated with GFR values in the euthyroid state $(r=-0.59 p<0.05$, $r=-0.70 \quad p<0.01$ ), respectively. Plasma and erythrocyte $\mathrm{Mg}^{2+}$ values were both found to be inversely correlated with $\mathrm{T}_{4}$ values in the euthyroid state $(r=-0.65 p<0.05, r=-0.75 p<0$. $01)$, respectively. Erythrocyte $\mathrm{Mg}^{2+}$ value was found to be inversely correlated with $\mathrm{T}_{3}$ value in the hypothyroid state $(r=-0.63, p<0.05)$. Erythrocyte $\mathrm{Mg}^{2+}$ value was found to be correlated with plasma uric acid value in the euthyroid state $(r=0.59, p<0.05)$.

\section{DISCUSSION}

Lowered levels of $\mathrm{T}_{3}, \mathrm{~T}_{4}$ and elevated TSH show that hypothyroidism has been established in rabbits, administered methimazole for 30 days. In rabbits as the normal range of plasma uric acid concentration is $0.58-0.78 \mathrm{mg} / 100 \mathrm{ml}$ our findings clearly show the development of hyperuricemia due to the induction of hypothyroid state (Akdemir et al. 2001). Hyperuricemia in hypothyroidism is a well-established phenomenon. In comparison to the prevalence reported in the general population, a significant increase of both hyperuricemia and gout has been reported in the hypothyroid patients in numerous clinical studies (Giordano et al. 2001). Plasma uric acid concentration increases due to an increase in uric acid production and/or a decrease in uric acid excretion (Facchini et al.
1991). Since the excreted amount of uric acid in urine has been found to decrease due to hypothyroidism, we consider that hyperuricemia does not result from overproduction but from decreased clearance in the hypothyroid state. As the fractional excretion of uric acid $\left(\mathrm{C}_{\mathrm{uA}} /\right.$ GFR) was found to be similar in hypothyroid and euthyroid states, it appears that decreased GFR accounts for the decreased uric acid clearance observed in the hypothyroid state. Hyperuricemia associated with hypothyroidism has also been shown to be due to the decreased renal uric acid clearance in earlier studies (Yokogoshi and Saito 1996; Giordano et al. 2001). Further, we observed that $T_{4}$ is positively correlated to plasma uric acid both in the euthyroid and hypothyroid states $\left(r=0.58^{*}, r=0.72^{* *}\right)$, respectively. This suggests that the decrease in metabolic rate and ATP turnover is greater than the decrease in glomerular filtration with depression in $\mathrm{T}_{4}$ in both the euthyroid and hypothyroid states.

As to post insulin infusion sum glucose values, regarded as a measure of the response to insulin, we observed no significant difference between the euthyroid and hypothyroid states of rabbits. However though non-significant the post-insulin infusion sum glucose value was found to be lowered to a considerable extent due to induction of hypothyroidism. The induced level of hypothyroid state might have been observed to cause a significant decrease with higher number of animals than used in this study. This suggestion is consistent with the fact that sensitivity to exogenous insulin might be increased due to slower degradation of insulin in hypothyroidism (Ingbor 1985). Shah and Cerchio (1973) suggested that glucose intolerance of the hypothyroid state is due to diminished insulin secretion rather than to resistance. Shah et al. (1975) examined the possibility of insulin resistance in hypothyroid patients and reported the absence of any evidence of resistance to the action of exogenously administered insulin in hypothyroid patients but an increased 
Table 2. Correlation coefficients among

\begin{tabular}{|c|c|c|c|c|c|}
\hline & $\mathrm{T}_{3}$ & $\mathrm{~T}_{4}$ & TSH & $\begin{array}{l}\text { Uric acid } \\
\text { (plasma) }\end{array}$ & $\begin{array}{l}\text { Uric acid } \\
\text { (urine) }\end{array}$ \\
\hline $\mathrm{T}_{3}$ & 1 & 0.21 & -0.04 & 0.42 & 0.38 \\
\hline $\mathrm{T}_{4}$ & & 1 & 0.26 & $0.58^{*}$ & 0.06 \\
\hline TSH & & & 1 & 0.06 & 0.44 \\
\hline Uric acid (plasma) & & & & 1 & 0.30 \\
\hline Uric acid (urine) & & & & & 1 \\
\hline \multicolumn{6}{|c|}{ Clearance of uric acid $\left(\mathrm{C}_{\mathrm{uA}}\right)$} \\
\hline \multicolumn{6}{|c|}{ Clearance of creatinine (GFR) } \\
\hline \multicolumn{6}{|l|}{$\mathrm{CuA} / \mathrm{GFR}$} \\
\hline \multicolumn{6}{|l|}{ Sum glucose } \\
\hline \multicolumn{6}{|l|}{ Triglycerides } \\
\hline \multicolumn{6}{|l|}{$\mathrm{Mg}^{2+}$ Plasma } \\
\hline $\mathrm{Mg}^{2+}$ Erythrocyte & & & & & \\
\hline
\end{tabular}

TABle 3. Correlation coefficients among

\begin{tabular}{|c|c|c|c|c|c|}
\hline & $\mathrm{T}_{3}$ & $\mathrm{~T}_{4}$ & TSH & $\begin{array}{l}\text { Uric acid } \\
\text { (plasma) }\end{array}$ & $\begin{array}{l}\text { Uric acid } \\
\text { (urine) }\end{array}$ \\
\hline $\mathrm{T}_{3}$ & 1 & $0.64^{*}$ & -0.17 & 0.50 & 0.36 \\
\hline $\mathrm{T}_{4}$ & & 1 & -0.05 & $0.72 * *$ & 0.34 \\
\hline TSH & & & 1 & 0.21 & 0.46 \\
\hline Uric acid (plasma) & & & & 1 & 0.56 \\
\hline Uric acid (urine) & & & & & 1 \\
\hline \multicolumn{6}{|c|}{ Clearance of uric acid $\left(\mathrm{C}_{\mathrm{uA}}\right)$} \\
\hline \multicolumn{6}{|c|}{ Clearance of creatinine (GFR) } \\
\hline \multicolumn{6}{|l|}{$\mathrm{CuA} / \mathrm{GFR}$} \\
\hline \multicolumn{6}{|l|}{ Sum glucose } \\
\hline \multicolumn{6}{|l|}{ Triglycerides } \\
\hline \multicolumn{6}{|l|}{$\mathrm{Mg}^{2+}$ Plasma } \\
\hline $\mathrm{Mg}^{2+}$ Erythrocyte & & & & & \\
\hline
\end{tabular}

sensitivity to insulin. Accordingly, the positive correlation of post-insulin infusion sum glucose with GFR $\left(r=0.75^{* *}\right)$ which was found to be lowered due to hypothyroidism indirectly supports the decrease in sum glucose values, reflecting increased sensitivity to exogeneous insulin in hypothyroidism.

On the other hand, the presence of a positive correlation between TSH and sum glucose values in the hypothyroid state $\left(r=0.76^{* *}\right)$ 
the parameters in euthyroid state

\begin{tabular}{ccccccc}
\hline $\begin{array}{c}\text { Clearance of } \\
\text { uric acid }\end{array}$ & $\begin{array}{c}\text { Clearance of } \\
\text { creatinine }\end{array}$ & CuA/GFR & Sum glucose & Triglycerides & $\mathrm{Mg}^{2+}$ Plasma & $\mathrm{Mg}^{2+}$ Erythrocite \\
\hline-0.01 & 0.04 & 0.18 & -0.43 & 0.14 & -0.26 & -0.41 \\
-0.26 & 0.46 & -0.13 & -0.46 & 0.54 & $-0.65^{*}$ & $-0.75^{* *}$ \\
-0.12 & -0.25 & 0.41 & -0.26 & $0.61^{*}$ & -0.19 & 0.20 \\
-0.36 & 0.45 & 0.17 & -0.50 & 0.32 & -0.33 & $0.59^{*}$ \\
0.35 & 0.02 & 0.51 & 0.05 & 0.11 & 0.31 & -0.05 \\
1 & 0.12 & 0.30 & 0.34 & -0.39 & 0.39 & -0.08 \\
& 1 & 0.08 & 0.03 & 0.37 & -0.59 & $-0.70^{* *}$ \\
& 1 & -0.26 & 0.07 & 0.21 & 0.13 \\
& & & 1 & -0.10 & 0.45 & 0.54 \\
& & & & 1 & -0.29 & -0.27 \\
& & & & & 1 & $0.61^{*}$ \\
\hline
\end{tabular}

the parameters in hypothyroid state

\begin{tabular}{ccccccc}
\hline $\begin{array}{c}\text { Clearance of } \\
\text { uric acid }\end{array}$ & $\begin{array}{c}\text { Clearance of } \\
\text { creatinine }\end{array}$ & $\mathrm{CuA} / \mathrm{GFR}$ & Sum glucose & Triglycerides & $\mathrm{Mg}^{2+}$ Plasma & $\mathrm{Mg}^{2+}$ Erythrocite \\
\hline 0.07 & -0.45 & -0.04 & -0.33 & $-0.60^{*}$ & -0.07 & $-0.63^{*}$ \\
-0.24 & 0.28 & 0.12 & -0.53 & -0.43 & -0.05 & -0.40 \\
0.16 & 0.54 & -0.47 & $0.76^{* *}$ & 0.21 & -0.52 & 0.002 \\
-0.10 & 0.02 & 0.15 & -0.33 & -0.19 & 0.05 & -0.40 \\
0.01 & -0.44 & 0.41 & -0.39 & 0.11 & -0.30 & -0.29 \\
1 & 0.20 & -0.10 & 0.11 & 0.10 & -0.22 & -0.32 \\
& 1 & -0.31 & $0.75^{* *}$ & 0.37 & 0.02 & 0.47 \\
& 1 & -0.35 & -0.02 & 0.001 & 0.01 \\
& & & 1 & 0.49 & -0.36 & 0.40 \\
& & & & & -0.11 & 0.51 \\
& & & & & & \\
\end{tabular}

${ }^{*} p<0.05 .{ }^{* *} p<0.01$

might appear contradictory to above. However, the well-established dose-dependent dual actions of thyroid hormones on various metabolic events should be considered. In relation to glucose utilisation thyroid hormones both potentiate the actions of insulin and also enhance the degradation of it. The decrease in potentiation of insulin, by thyroid hormones may account for the positive correlation between TSH and sum glucose seen in the 
hypothyroidism-induced animals.

We observed that development of the hypothyroid state was accompanied by a decrease in triglyceride concentration of the plasma. In accordance with this finding Dory and Roheim (1981) and Rosenqvist et al. (1981) also reported reduction in plasma triglycerides in experimental hypothyroidism. Plasma triglyceride concentration decreases due to a decrease in production and secretion of VLDL from liver and/or an increase in lipoprotein lipase (LPL) activity. In the hypothyroid state the decrease in plasma triglyceride concentration could be due to the decreased delivery of VLDL to the circulation. As hypertriglyceridemia is generally associated with insulin resistance decreased triglycerides in this study, indirectly support the absence of insulin resistance in the induced level of hypothyroid state. On other hand, in the hypothyroid state we observed an inverse correlation between $\mathrm{T}_{3}$ and triglyceride concentrations. Which implies that serum triglycerides tend to increase as hypothyroid state becomes more severce. In the euthyroid state in line with this correlation, we observed a positive correlation between TSH and triglyceride. These findings are again consistent with the dose-dependent dual actions of thyroid hormones. Both the synthesis and degradation of lipids are depressed in states of thyroid hormone deficiency. However, as the latter is especially depressed the net effect is an increase in the stores of most lipids and usually their concentrations in plasma. Accordingly Ingbor et al. (1985) reported that hypertriglyceridemia in hypothyroidism is due to lowered lipoprotein lipase activity which necessitates availability of adequate thyroid hormones.

As to $\mathrm{Mg}^{2+}$, the induction of hypothyroidism caused an increase in plasma concentration, whereas a decrease in the erythrocyte concentration. We have previously also reported an increase in plasma $\mathrm{Mg}^{2+}$ concentration on hypothyroidism induction (S imşek et al. 1997). Our findings are consistent with that thyroid hormones by increasing renal plasma flow and GFR and also by activating the reninaldosterone system cause increased $\mathrm{Mg}^{2+}$ excretion and thus lower the plasma concentration (Simssek et al. 1997). The inversely correlated plasma $\mathrm{Mg}^{2+}$ concentration with both GFR $\left(r=-0.59^{*}\right)$ and $\mathrm{T}_{4}\left(r=-0.65^{*}\right)$ in the euthyroid state are consistent with these actions of thyroid hormones. Erythrocyte $\mathrm{Mg}^{2+}$ concentration was also found to be inversely correlated to GFR $\left(r=-0.70^{* *}\right)$ and $\mathrm{T}_{4}\left(r=-0.75^{* *}\right)$ in the euthyroid state. These findings together with the correlated plasma and erythrocyte $\mathrm{Mg}^{2+}$ values $\left(r=0.61^{*}\right)$ suggests that changes in erythrocyte $\mathrm{Mg}^{2+}$ are to a certain extent, secondary to the changes in plasma $\mathrm{Mg}^{2+}$ in the euthyroid state. Similar to that observed in the euthyroid state, we observed that erythrocyte $\mathrm{Mg}^{2+}$ concentration was inversely correlated with $\mathrm{T}_{3}$ $\left(r=-0.63^{*}\right)$ in the hypothyroid state.

In accordance with our findings Zumkley and Lehnert (1984) also reported lowered erythrocyte $\mathrm{Mg}^{2+}$ concentration in the hypothyroid state as compared to the euthyroid state. It is important to note that for interpretation of data on erythrocyte $\mathrm{Mg}^{2+}$ in the hypothyroid state, the lowered metabolic activity of the erythrocyte and the decreased renal excretion should both be considered (Ingbor 1985). With the induction of hypothyroidism the lowered metabolic activity in the erythrocyte might have led to the decreased intraerythrocytic concentration. With the progression of the hypothyroid state, the decreased $\mathrm{Mg}^{2+}$ excretion might have caused an increase in $\mathrm{Mg}^{2+}$ concentration of primarily plasma and secondarily of erythrocytes (Shibutani et al. 1989). The inverse correlation that we observed between $\mathrm{T}_{3}$ and erythrocyte $\mathrm{Mg}^{2+}$ in the hypothyroid state might be interpreted in favor of this suggestion. Additionally, the positive correlation of erythrocyte $\mathrm{Mg}^{2+}$ with plasma uric acid in the euthyroid state $\left(r=0.59^{*}\right)$ imply the similar pattern of change in these parameters, the major determinants acting reciprocally, being renal excretion 
and metabolic activity.

Importantly, both hyperuricemia and decreased intracellular $\mathrm{Mg}^{2+}$ have been associated with insulin resistance in relation to aging, hypertension and obesity in numerous experimental and clinical studies (Paolisso et al. 1990, 1995; Resnick et al. 1990; Paolisso and Barbagollo 1997). However on the basis of our data on post-insulin infusion sum glucose and triglycerides, we observed that insulin resistance did not develop in the hypothyroid state induced in this experimental study. In this regard, we also observed that the consideration of dosedependent dual actions of thyroid hormones is important.

To conclude the increase in plasma uric acid observed due to hypothyroidism is considered to be secondary to decreased renal excretion. As clearly evident from this study, hyperuricemia of hypothyroidism should not be regarded as an indicator of insulin resistance. Importantly, the measured levels of biochemical parameters affected by both metabolic activity and renal excretion must be interpreted with caution in thyroid hormone disorders.

\section{References}

Akdemir, H., Aşık, Z., Paşaoğlu, H., Karaküçük, İ., Öktem, İ.S. \& Kemal Koç, R. (2001) The Effect of allopurinol on focal cerebral ischaemia: An experimental study in rabbits. Neurosurg. Rev., 24, 131-135.

Institute of laboratory animal resources commission on life sciences national research council (1996) Guide for the care and use of laboratory animals. Washington, D.C., Animals housing and management. National Research Council, pp. 21-55.

Dory, L. \& Roheim, P.S. (1981) Rat plasma lipoprotein and apolipoproteins in experimental hypothyroidism. J. Lipid Res., 22, 287-296.

Erickson, A.R., Enzenauer, R.J., Nordstrom, D.M. \& Merenich, J.A. (1994) The prevalence of hypothyroidism in gout. Am. J. Med., 97, 231 $-234$.

Facchini, F., Chen, I., Hollenbeck, C. \& Reaven, G.M. (1991) Relationship between resistance to insulin-mediated glucose uptake, urinary uric acid clearance and plasma uric acid concentration. JAMA, 266, 3008-3011.

Giordano, N., Santacroce, C., Mattii, G., Geraci, S., Amendola, A. \& Gennari, C. (2001) Hyperuricemia and gout in thyroid endocrine disorders. Clin. Exp. Rheumatol., 19, 661-665.

Ingbor, S.H. (1985) The Thyroid Gland. In: Textbook of Endocrinology, edited by J.D. Wilson \& D.W. Foster, Philadelphia, W.B. Saunders, 682-815.

Mikkelson, W.M., Dodge, H.J. \& Valkenburg, H. (1965) The distribution of serum uric acid values in a population unselected as to gout or hyperuricemia: Tecumseh, Michigan 1959 -1960. Am. J. Med., 39, 242-251.

Modan, M., Idalkin, H., Karasık, A. \& Lusky, A. (1987) Elevated serum uric acid - a faced of hyperinsulinemia. Diabetologia, 30, 713-718.

Paolisso, G., Scheen, A., D'onofrio, F. \& Lefebure, P. (1990) Magnesium and glucose homeostasis. Diabetologia, 33, 511-514.

Paolisso, G. \& Ravussin, E. (1995) Intracellular magnesium and insulin resistance: results in Pima Indians and Caucasians. J. Clin. Endocrinol. Metab., 80, 1382-1385.

Pailosso, G., Galzerano, D., Gambardella, A., Gentile, S., Lama, D. \& Varricchio, M. (1995) Low fasting and insulin-mediated intracellular magnesium accumulation in hypertensive patients with left ventricular hypertrophy: role of insulin resistance. J. Hum. Hypertens., 9, 199-203.

Paolisso, G. \& Barbagollo, M. (1997) Hypertension, diabetes mellitus and insulin resistance: The role of intracellular magnesium. Am. J. Hypertens., 10, 346-355.

Resnick, L.M., Gupta, R.K., Gruenspan, H., Alderman, M.H. \& Laragh, J.H. (1990) Hypertension and peripheral insulin resistance. Possible mediating role of intracellular free magnesium. Am. J. Hypertens., 3, 373-379.

Rosenqvist, U., Mahler, R. \& Carlson, L.A. (1981) Lipid transport in the hypothyroid rat as reflected by the serum concentrations of free fatty acids, lipoproteins, lecithin-cholesterol acyltransferase and lipoprotein lipase activity in adipose tissue. J. Endocrinol. Invest., 4, 75 $-78$.

Shah, J.H. \& Cerchio, G.M. (1973) Hypoinsulinemia of hypothyroidism. Arch. Intern. Med., 132, 
657-661.

Shah, J.H, Motto, G.S., Papagiannes, E. \& Williams, G.A. (1975) Insulin methabolism in hyperthyroidism. Diabetes., 24, 922-925.

Shibutani, Y., Yakota, T., Jijima, S., Fujioka, A., Katsuno, S. \& Sakamoto, K. (1989) Plasma and erythrocyte magnesium concentrations in thyroid disease: Relation to thyroid function and the duration of illness. Jpn. J. Med., 28, 496-502.

Şimşek, G., Andican, G., Karakoç, Y., Yiğit, G., Hatemi, H. \& Candan, G. (1997) Calsium, magnesium and zinc status in experimental hypothyroidism. Biol. Trace Elem. Res., 60, 205-213.

Vuorinen-Markkola, H. \& Yki-Järvinen, H. (1994) Hyperuricemia and insulin resistance. $J$. Clin. Endocrinol. Metab., 78, 25-28.

Yokogoshi, Y. \& Saito, S. (1996) Anormal serum uric acid level in endocrine disorders. Nippon Rinsho, 54, 3360-3363.

Zumkley, H. \& Lehnert, H. (1984) Magnesium, potassium and hormonal regulation. Magnesium, 3, 239-248. 